\title{
PRIMEROS TEXTOS PUBLICADOS DE CARMEN MARTÍN GAITE EN LA REVISTA TRABAJOS Y DÍAS (SALAMANCA, 1946-1951)
}

\section{Dolores Romero López}

\author{
Universidad Nacional de Educación a Distancia
}

Hace ya algunos años publiqué un artículo titulado «Un tributo al análisis de las revistas españolas de posguerra: Trabajos y Días (Salamanca, 1946-1951)» (Romero López, 1995). Se trata de una investigación que tenía por objeto analizar y dar a conocer la existencia de una revista universitaria salmantina que, en honor a la obra de Heríodo, se llamó Trabajos y Días. Este estudio fue un intento de completar la publicación de Jordi Gracia (1994), Crónica de una deserción. Ideología y política en la prensa universitaria del franquismo (19401960), donde se analizan otras revistas similares como Alférez, Alerta, Estilo, Laye, Alcalá, Qvadrante, La hora, Theoría y Acento cultural. Rafael Sánchez Ferlosio, Ignacio Aldecoa, Jesús Fernández Santos, Alfonso Sastre, Juan García Hortelano, Carlos Barral, José María Castellet, José Manuel Caballero Bonald, Carmen Martín Gaite y otros tantos iniciaron su carrera como escritores en aquellas revistas de posguerra. De ellas salió la estética del realismo y en sus páginas se expresaron los que serían precursores de las ideas democráticas. 
La bibliografía sobre la revista Trabajos y Días es muy escasa. Apenas encontramos una reseña en el recopilación de Manuel Peláez del Rosal (1980), otra en el libro coordinado por Teresa Santander (1986) y un escueto artículo que Fernando Rodríguez de la Flor (1980) publicó en el diario salmantino El Adelanto. La revista surgió al socaire de las tertulias sabatinas de La Exedra. Tal denominación se debe a la construcción de planta semicircular que tenía el extinto Café Castilla, donde se celebraban. De dichas conversaciones surgió la necesidad de hacer una publicación donde quedaran plasmadas sus opiniones. A pesar de que la revista nace sin mentor, parece que fueron Antonio Tovar y Manuel García Blanco, por lo que cita Teresa Santander, los que promovieron la publicación y buscaron los medios económicos necesarios para soportarla. En Trabajos y Días publican profesores: Alfredo Carrato, Alonso Zamora Vicente, Ángel de Apráiz, Antonio García Boiza, Antonio Tovar, Pedro Laín Entralgo, Fernando Lázaro Carreter, Francisco Maldonado de Guevara, José Camón Aznar, Manuel García Blanco, Luis S. Granjel, etc. y los entonces alumnos: Agustín García Calvo, Concha Giner, Natalia Guilarte ', Luis Leocadio Cortés y Vázquez, Manuel Palomar Lapesa, Manuel Alvar, Carmen Martín Gaite, Virgilio Bejarano, etc., hombres y mujeres que con el tiempo se erigieron en la elite intectual de un país sumido en penuria.

El talante ideológico de la revista, subvencionada por el Gobierno Civil, fue siempre de diálogo y entendimiento como lo demuestra este texto anónimo:

En el suplemento político de este número se habla de la evolución que está realizando nuestro régimen. Tal vez sea ésa la razón por la que nos sentimos obligados a explicar quiénes somos y qué queremos con este periodiquillo nuestro, en el que tal vez no haya más que unas ilusiones de juventud. Nuestro periódico hace media docena de años hubiera estado mucho más claro. No hubiera sido necesario que anduviéramos con circunloquios y explicaciones más o menos misteriosas. Entonces se repetía mucho que nuestro movimiento no era ni un movimiento de derechas ni un movimiento de izquierdas, que el común denominador que se buscaba era el de ser españoles y sentir la vida nacional con un mínimo de angustia, que no se trataba de excluir a nadie, ni de coartar dogmáticamente una porción de campos que Dios ha dejado a la actuación de los hombres. [...] Precisamente se pretendía en esta revista recoger las diversas vibraciones de las generaciones que llegan a la Universidad, sin extremar los tópicos de la formación, hoy en una moda tan peligrosa y de efectos tan contraproducentes, como la repetida experiencia demuestra. Son precisamente personas que se las dan de liberales y de antitotalitarios los que andan expurgando y espulgando en nuestras páginas con celo digno de mejor causa. Nada oscuro hay aquí. Todo el mundo sabe quiénes somos y si de algo nos jactamos es de poder entendernos con todo el mundo. Ni hemos querido molestar nunca a nadie y si alguien nos parece digno de alabanza, no andamos averiguando lo que es o ha sido. Esto es todo (núm. 6, s. p.).

1 Amiga de Carmen Martín Gaite, citada por la novelista con el mismo nombre y apellidos en su obra Entre visillos. 
En el siguiente cuadro se pueden apreciar los números publicados que manifiestan el fervor con el que se comienza y la falta de financiación con la que se termina:

\begin{tabular}{lcccc}
\hline Año & Número & Número & Número & Número \\
\hline 1946 & 1 febrero & 2 marzo-abril & 3 mayo & 4 diciembre \\
\hline 1947 & 5 enero-febrero & 6 marzo-abril & 7 junio & \\
\hline 1948 & 8 enero & 9 abril-mayo & & \\
\hline 1949 & 10 enero & 11 abril-mayo & \\
\hline 1950 & 12 enero & 13 marzo-abril & 14 diciembre & \\
\hline
\end{tabular}

La revista, pues, consta de quince números, repartidos irregularmente entre los años 1946 y 1951.

Los temas soportan esa tensión entre maestros / alumnos, pasado / presente, España / Europa y tradición / modernidad. Destacan varios artículos o reseñas sobre autores de la entonces llamada Generación del 98, algunos sobre el Grupo de 1927 y la preocupación por la coetánea novela realista y la poesía de visos sociales. En general, la revista es un notable intento de reconstrucción intelectual del país, de ahí su título.

\section{CARMEN MARTÍN GAITE Y TRABAJOS Y DÍAS}

Carmen Martín Gaite nació en la ciudad de Salamanca el ocho de diciembre de 1925, a las doce de la mañana, en la casa que sus padres tenían en Plaza de los Bandos. Inició sus estudios de bachillerato en el Instituto Femenino, cuyo ambiente describió posteriormente en su libro Entre visillos. Allí disfrutó del saber impartido por dos magníficos profesores: Rafael Lapesa y Salvador Fernández Ramírez, a ellos les debe, según manifiesta en su libro Agua pasada, el esmero con que se entregó a los ejercicios de redacción y su vocación definitiva por la literatura. En 1943 comenzó su carrera de Filología Románica en la Universidad de Salamanca. Fue condiscípula de Ignacio Aldecoa y del poeta Agustín García Calvo. En el verano de 1948, al terminar sus estudios universitarios, Carmiña, como la conocían sus compañeros, se desplazó hasta la Universidad de Cannes, donde disfrutó de una beca de estudios. El sabor de aquella libertad juvenil determinará su marcha a Madrid con la excusa de estudiar su doctorado. De noviembre de 1948 a la primavera de 1949 vivió en Madrid. En mayo la enfermedad del tifus, acompañada de 
altísimas fiebres, le obliga a regresar a Salamanca. Pero durante el otoño de ese año, la familia se trasladó definitivamente al piso de la calle Alcalá, en Madrid.

Esos breves datos biográficos, a los que, entre otros, alude la novelista en Agua pasada (1993: 11-35), adquieren notable importancia para comprender su entrañable vínculo con Trabajos y Días. Las colaboraciones de Carmen Martín Gaite en la revista se reducen a tres en su época de estudiante: un poema titulado «La barca nevada» (1947a), alguna traducción del rumano (1947b) y una narración cuyo título es «Desde el umbral» ((1948). Pasajes de más fortuna fueron los publicados estando ella ya en Madrid, después de licenciarse. Me refiero a los poemas: «En mi vejez» (1949a) y «Destello» (1949b). En 1949 la autora regresa a Salamanca para reponerse de una enfermedad en casa de sus padres. Pero ya su cuento «Historia de un mendigo» (1950) fue publicado después de que la familia se mudara a la capital durante el otoño de 1949. Por tanto, Carmen Martín Gaite mantuvo con quienes siguieron redactando Trabajos y Días una cordial relación que le llevó a participar en la revista aún habiendo perdido su vínculo. De todos los textos publicados en esta revista, únicamente los poemas «En mi vejez» $\mathrm{y}$ «Destellos» fueron recopilados posteriormente en su libro A rachas, con acertadas modificaciones. Las demás publicaciones fueron olvidadas y consideradas por la autora como algo «cursi y malísimo».

En la bibliografía consultada sobre la escritora (Alemany, 1990; Chown, 1990; Ciplijauskaité, 1988; Lipman, 1987; Lluch, 2000; Martinell, 1993; Nichols, 1992; Puente, 1994; Servodidio, 1983) siempre se hace referencia a estas colaboraciones en la revista universitaria, pero nadie, que sepamos, hasta ahora, se ha atrevido a husmear en aquellos textos y volver a publicarlos. Ella misma los menciona en su obra Agua pasada, pero pocos investigadores se han esmerado en recopilar los escritos perdidos en las páginas de aquellas publicaciones periódicas donde en su día colaboró ${ }^{2}$.

Cuando en 1995, le pedí su opinión para volver a publicar sus primeros textos me contestó, en carta personal, lo siguiente:

Aunque un poco a regañadientes, le doy el permiso que me pide. No he vuelto a leerlo nunca, y casi ni me acordaba del título, pero por el vago recuerdo que tengo me parece que "Historia de un mendigo" era un cuento muy cursi y malisimo del que me voy a avergonzar. No sé qué provecho pueden sacar de esta vergüenza mía los demás, pero también conozco la tenacidad inquebrantable de

2 Sólo conozco la transcripción de unos fragmentos de El libro de la fiebre recopilados Jordi Gracia (1994) y reproducidos en su antología Crónica de una deserción. Ideología y política en la prensa universitaria del franquismo (1940-1960). 
aquellos desenterradores de fantasmas, y estoy en un momento en el que lo último que me apatece es discutir. Así que haga lo que quiera. Sólo le pido que en su artículo no sea hagiográfica y le pegue un palo a "Historia de un mendigo", que creo que se los merece todos. Pero no sé si seré capaz de convencerla [...]

Aquellas palabras y otras circunstancias personales hicieron que olvidara mi intención de publicar los textos. Ahora creo que conviene publicarlos, en primer lugar, porque son las primeras letras impresas de una gran escritora; después, para deshacer malentendidos de la crítica que se terminan pasando de unos a otros y de generación en generación; y, por último, para poder trazar su trayectoria literaria completa, que abarca tres facetas intelectuales (narradora, poeta y traductora).

\section{LAS TRADUCCIONES}

El elenco de autores traducidos en Trabajos y Días se circunscribe a Goethe, Heine y Hölderling que mantenían vivo el reclamo de la cultura clásica del espíritu germánico. Las traducciones del rumano que Carmen Martín Gaite realiza están motivadas por una circunstancia personal e histórica: el rumano Aurelio Rauta impartía clases de dicha lengua en la Facultad de Letras. Aurelio Rauta tuvo que exiliarse de Rumanía para no enfrentarse con el nuevo régimen promarxista. La España de Franco le dio cobijo. Rauta es colaborador activo de la revista e instigador, sin duda, de la voluntad de Carmen Martín Gaite, quien debió sentir, gracias a él, la necesidad de adaptar dos fragmentos del poeta rumano Tudor Arghezi, del que señala la traductora:

\footnotetext{
Nació en Bucarest en 1880, el día 21 de mayo. En el año 1896 frecuentaba el círculo literario Literatorul de Al. Macedonski donde conoce a Gala Galactión. Hacia 1899 es ayudante de químico en una fábrica de azúcar. Luego monje en el monasterio Cernica. Después de cuatro años de diácono en la metropolitana Bucarest abandona el país en 1905, realizando un viaje por Francia, Suiza, etc. Fue encarcelado por complicidad antimonárquica pasando dos años en la cárcel. Su obra poética fue reunida últimamente en un tomo titulado Versuri. Escribió algunas novelas (Martín Gaite, 1947b: s.p.).
}

Efectivamente, Ion N. Teodorescu, llamado Tudor Arghezi, publicó varios libros de poemas líricos: Poemas variados (1927), Flores de moho (1931), Farándulas (1939) y algunos textos en prosa: Iconos de madera y La puerta negra (1930), recuerdos de su vida monástica y de su estancia en la cárcel, donde estuvo preso por motivos políticos. Los fragmentos que transcribo, a pesar de pertenecer a un poeta foráneo, recuerdan los 
desastres de la Guerra Civil española. Las fosas comunes, el hambre que asoma en las famélicas figuras de los vivos, la soledad, el miedo y el irónico matiz religioso apuntan con sarcasmo a la injusticia que engendra la vida. Poemas de tono desarraigado y estremecedor que debieron impactar a la joven traductora, pues ella misma recuerda que su familia pasó toda la guerra en Salamanca:

con bastante miedo, debido a las ideas liberales de mi padre y de todos sus amigos, muchos de los cuales -entre ellos don Miguel de Unamuno- sufrieron persecución y cárcel por parte del general Franco, que tenía en Salamanca su Cuartel General y reprimió -como es sabido-cualquier conato de liberalismo. A mi padre no lo llegaron a encarcelar porque no pertenecía a ningún partido político, pero siempre nos estaba aconsejando que no habláramos con nadie de sus opiniones antimilitaristas y la casa se había convertido en una especie de refugio, que reforzó nuestros lazos familiares. A un hermano de mi madre, Joaquín Gaite - discípulo y amigo de don Miguel de Unamuno-lo fusilaron en agosto de 1936 por tener carnet del partido socialista (Martín Gaite, 1993: 15).

Probablemente fue el recuerdo de escenas de hambre e infortunio lo que la motivó a publicar estas traducciones:

Los muertos (Martín Gaite, 1947b)

Salen los muertos...

Son diez,

Y pasan bajo el arco de la puerta,

Hombro con hombro

Cada dos en sus ataudes (sic),

Sin madre, sin cura, sin cruz.

Van juntos

Con hielo y con luna.

A los diez los han borrado de la lista

$Y$ los han echado al universo,

Con los brazos inertes cruzados

Sobre la tripa desnuda.

Vedlos. Hambrientos, no saben de hambre

$Y$ rígidos olvidaron el frío.

Alguien curará en el cielo

Sus amoratadas heridas. 
El portero, en el camino los detiene

Y los cuenta con la punta del bastón.

Afuera el caballo, como tallado en madera, parece muerto.

Y también el hombre que agarra las riendas.

[i]Adiós! Id en paz hacia la fosa común.

Que la tierra os sea más amiga

Que las manos que os castigaron,

Que los curas que os han negado su oración.

$Y$ estad alertas.

No os extravieis (sic) en el camino.

Porque mañana por la noche, quizá está noche.

Cuando se enciendan las estrellas de cera.

Pasareis (sic)

A un nuevo juicio.

\section{Duhovniceasca (Martín Gaite, 1947b)}

¿Qué noche tan densa y tan pesada!

Alguien ha llamado en el fondo del mundo.

¿Realmente Alguien? ¿O sólo ilusión mía?

¿Quién viene andando sin luz,

Sin luna, sin antorcha

$Y$ ha chocado contra los álamos del jardín?

¿Quién se acerca sin ruido de pisadas,

Como un alma errante?

¿Quién está ahí? ¡Responde!

¿De donde (sic) vienes y por donde (sic) has entrado?

¿Eres tú madre? Tengo miedo

[i]Madre buena, madrecita!

[i]Has vuelto porque te aburrías en la tumba!...

Mira. Todos dejaron de existir;

Desde que te fuiste, todos se han ido yendo...

Se acostaron como tú, han anochecido,

[i]Se han dormido del todo!

El perro también giró en torno a su hocico

$Y$ cayó. Perecieron las mazorcas, 
Se secaron la albahaca y los morales, Volaron del alero los gorriones,

Dijeron adiós a la casa de las golondrinas y los vencejos,

Las colmenas están desiertas,

Pardean los álamos

Hasta se han derrumbado las paredes y el cortijo está podrido...

[i]Eh! ¿Quién atravesó el huerto

Y quien se ha detenido? [i]Dí! ¿Por que (sic) te paras?

¿Qué quieres? [¿] Quien (sic) eres tú

Que vienes invisible y mudo como en los cuentos?

Aquí ya no vive nadie

Desde hace veinte años...

Sólo yo estoy, esparcido entre las espinas y los terrones...

También murió el número de la puerta.

Y la campana y la llave y el candado.

Acaso eres un fantasma

Que nunca vino por aquí. Ahora siento

Cómo me miras a través de la oscuridad

Taladrando mis pensamientos todos.

[i]Eh! [¿]Quien (sic) está ahí vestido de tinieblas?

¿Quién araña el muro con su carne,

Con su dedo como un clavo

$Q$ ue repercute en mis heridas?

¿Quien (sic), errante y cansado delante de la puerta?

Tengo la lengua áspera como de ceniza.

No puedo andar más.

$Y$ tengo sed. Vecino, ábreme tu puerta.

Mira sangre y gloria.

Mira maná, y veneno.

He huído (sic) de la cruz,

Tómame. Escóndeme en tus brazos.

\section{LOS POEMAS}

La recopilación de los poemas de Carmen Martín Gaite se llevó a cabo, gracias a la iniciativa de Jesús Munárriz, en la colección Hiperión en 1976. 
Hasta entonces sus poemas habían quedado dispersos en libretas, apuntes, cartas y la publicación esporádica de alguno de ellos, de ahí que esa cuarentena de poemas se titulara $A$ rachas, que define a la perfección lo que a rachas fue escrito y publicado.

Son tres los poemas impresos por primera vez en Trabajos y Días. Dos, con algunos cambios, pasaron la criba y vieron la luz, con certeras modificaciones, en su libro $A$ rachas. En ellos se respira la triste melancolía del paso del tiempo, el anhelo por salir de la rutina en busca de un espacio inexplorado y una galante mirada a la naturaleza simbolizada en la nieve, las flores y los lirios. La soterrada y fina sensibilidad marca el ritmo de unos versos que ganan con el tiempo belleza por ser el primer latido de la expresión personal.

La barca nevada (Martín Gaite, 1947a)

Nos hemos despertado, y la luz de invierno amanecía de nuevo en las rendijas.

Por caminos del aire, leve y tímida, se despeinó la nieve y durmió en la ventana.

Otro invierno ha bajado de puntillas

a posarse en el río,

$y$ en la noche ha tejido

cristal de quieta losa, extendido silencio.

Mirad la pobre barca prisionera del agua endurecida.

Sola y blanca de canas

mira correr las nubes con envidia.

bien nubes desligadas,

que os destrenzáis tan jóvenes

sobre la barca inútil!-

Sí. De nuevo el invierno.

Tomad entre los labios

su áspero jugo oculto

animado en la (sic) nieblas y en las ramas sin savia.

[i]Abrid las puertas todas

y que entre oscuramente

esa canción intensa de promesa

y letargo fecundo! 
Tiempo duro y dichoso para los corazones que esperan el milagro, apenas presentido, de otros días. Es difícil andar entre la nieve, subiendo por camino predegoso (sic) pero alli están las cumbres, muy lejos, sonrosadas en la tarde. Un día - lo sabemosDios tocará los brazos, hoy pobres y desnudos, de las ramas, y los hará llenarse de gusanitos verdes

七mbrión de reciente primavera-. Vivid la espera.

El aire con sus manos florecidas soltará un día el hielo dulcemente - canción de espuma alborotada y libre en pedazos fundidos vida abajo-. $Y$ a tí vendrá a librarte, triste barca olvidada de la orilla. Empujará tu cuerpo por repetidas rutas - [i]tan nuevas sin embargo!-, Y el agua resurgida tibia y dócil, amasada con sol, cederá al roce de tus alas niñas, y romperás sin llanto el misterio fluido de sus venas. Y palabras de amor dirá, a tu paso, el inclinado chopo.

Nada está muerto aún bajo la escarcha.

La vuelta de las cosas que dormían su plenitud, desgranará los aires como trinos abiertos y gozosos. Pero vivid la espera del invierno. $Y$ que ella os purifique.

\section{Carmiña}

En mi vejez (Martín Gaite, 1949a)

Cuando el tiempo de flor

venga a fundir la nieve en la montaña, 
ya no te esperará mi corazón, alondra.

([i]Ay! ¿Cómo eran sus labios?

cantará el surtidor).

De nuevo el mismo sol

se vendrá a los tejados

perezoso

herido por el grito de los niños

que juegan en la playa.

$Y$, como hoy, la mañana

despertará - encendida-

por fuera de mis ojos.

Pero mi corazón,

alondra,

ya no te esperará ${ }^{3}$.

\section{Carmiña}

Mayo 1948

\section{Destello (Martín Gaite, 1949b)}

Hoy habláis otra lengua,

lirios que os despeináis bajo la lluvia.

Me apresáis con vosotros

igual que si me viera en un espejo.

$Y$ tengo que dejaros.

Tiran de mí precisamente ahora

que acabo de encontrarme

$\longrightarrow$ pequeña, pura-

entre vuestras corolas.

Voy a cerrar los ojos,

—no deshagan la imagen-.

$Y$ me iré sin miraros otra vez.

[i]Ayi Cuando vuelva a veros

¿sabré ya comprender este lenguaje vuestro

que un minuto ha rasgado mi tiniebla

${ }^{3}$ Publicado en $A$ rachas con leves cambios que mejoran su calidad. TIEMPO DE FLOR: «Cuando el tiempo de flor / venga a fundir / la nieve en la montaña, / ya no te esperará mi corazón, / alondra. / ¡Ay! ¿cómo eran sus labios? / - cantará el surtidor. / De nuevo el mismo sol / se vendrá a los tejados, perezoso, / herido por el grito de los niños / que juegan en la plaza. / Y, como hoy, / la mañana despertará encendida». 
oh lirios despeinados por la lluvia? ${ }^{4}$

Carmiña Septiembre 1947

\section{LAS NARRACIONES}

Dos son las narraciones que Carmen Martín Gaite publicó en Trabajos y Días. El primer relato, «Desde el umbral» (Martín Gaite, 1948), centra su preocupación en la rutina diaria vivida de la Facultad de Filología donde la protagonista estudia. Se trata, pues, de un fragmento autobiográfico que refleja la angustia de la autora ante el monótono paso del tiempo. El guiño de la primavera abre las esperanzas de un corazón inexperto que ansía cambiar su espacio vital —el Seminario de Románicas-, anclado en el ayer, por la posibilidad y el anhelo del mañana. El relato, en el que se mezclan atinadamente reflexiones sobre la vida con simbólicas descripciones de la naturaleza, se gesta en torno al gozne de un presente que debe templarse en el despertar futuro.

El cuento «Historia de un mendigo» (Martín Gaite, 1950) asienta las bases de lo que serán las fundamentales preocupaciones de la escritora salmantina: la oposición campo/ciudad, la rutina, la incomunicación, el desacuerdo entre lo que se hace y lo que se sueña y el miedo a la libertad. El mendigo simboliza el sufrimiento de un ser humano despedazado y perdido en el seno de una sociedad que le es hostil y en la que, por otra parte, se ve obligado a insertarse. Se narra un momento cualquiera, gris, insignificante, de un ser vulgar y anodino que ha perdido su capacidad de comunicación con la sociedad y no logra afianzar su autodeterminación. En cuanto a su personalidad destaca el miedo a ser observado, a hablar con las gentes, a sentir afecto por el perrucho que le acompaña. El mendigo rehuye la mirada de los otros y se refugia en su fiel perro que se convierte en símbolo de él mismo y de su relación con la sociedad. Al final se le niega la esperanza de cambiar su vida, de hacer realidad sus sueños y se encamina al fatal encuentro con la muerte. El mendigo posee la óptica privilegiada del flâneur que le permite pasear, observar y analizar a los seres que le circundan. El estudiante de medicina, la muchacha del sombrerito rojo, adolescentes, jóvenes chicas con sus novios, las gentes que se apresuran hacia los tranvías, los

4 Poema recopilado en $A$ rachas con algunas variaciones respecto al original que favorecen el estilo. DESTELLO: «Hoy habláis otra lengua, / lirios que os despeináis / bajo la lluvia. / Miré vuestras corolas: / «otros son tierra y cal, / yo soy el pino, / la mañana y la música / - leí- soy el instante». / Voy a cerrar los ojos, / no olvidé la lectura, / no se enturbie la imagen, / y me iré sin miraros otra vez. / iAy! Cuando vuelva a veros, / ¿sabré ya comprender este lenguaje vuestro / que un minuto ha rasgado mi tiniebla, / lirios que os despeináis bajo la lluvia?» 
niños que juegan constituyen una gran fotografía social, con relación a la que el mendigo (el artista) es un excluido al que únicamente se le permite soñar y emborracharse. Esa necesidad del narrador de ubicarse fuera para tener la perspectiva que le permita contar se manifiesta en la elección de palabras como «umbral», «balcones» o «visillos». La escritora se aproxima así a la realidad social de la posguerra. Ese mendigo es un vencido de la contienda civil cuyo defecto no reside en su falta de palabras, sino en su miedo a comunicarse con los demás, supuestos vencedores del conflicto, lo que le lleva a replegarse sobre las ruinas de su memoria. Si «Desde el umbral» es testimonio de las inquietudes que le motivan a respirar nuevos aires, «Historia de un mendigo», en cambio, cumple la función de testimoniar lo social. Al focalizar el asunto del relato en las lacras sociales, la escritora azuza el malestar de la conciencia colectiva y pone de manifiesto la eficacia de la literatura como instrumento de acción social.

Desde el umbral (Martín Gaite, 1948)

Pasamos media vida mirando hacia allá, imaginando. Tanto que nos parece que ya nos hemos ido.

$Y$ un día, al alzar los ojos, estamos aún en el mismo sitio. Acostumbradamente se cruzan nuestros trenes y cada instante es una despedida.

Sí. Ahí está todavía Muriel, saludándonos desbordado y alegre por los pasillos de la Facultad. $Y$ aquí los mozárabes diciendo yanair y conelyo como niños tontitos que aprendiesen a hablar repitiendo lo mismo un día y otro. $Y$ enfrente la Catedral blanca de nieve, gozosa de sol, recortada y violeta al poniente, como si pensara.

Nos han dicho que Adrados ya es catedrático y que Alvar lo va a ser enseguida. Se llaman así, Adrados y Alvar, y nos acordamos muy bien de cuando eran estudiantes de cuarto curso. También algunas chicas que estudiaban entonces, ahora tienen un hijo. Que esto es más importante todavia.

...Y nosotros escuchamos las noticias con dulce e inconsciente admiración, respiramos bien fuerte y nos sacudimos el polvo cantando. Cantando al azar. Porque nada está colmado, porque aún no hemos llegado a ningún sitio.

(Tampoco llegaremos luego, ni nunca; pero nos parecerá que sí). $-Y$ podemos hacer mucho ruido para que todos sepan que estamos aquí todavía.

No se trata de intentar hacer eterno el tiempo. De intentar guardarse unas horas que sólo son para que hayamos sabido irlas cogiendo y soltando mien- 
tras pasaban intensas y redondas. Que no valen por ellas mismas sino por lo que nos han enseñado al beberlas.

Pero sí es tiempo de mirar alrededor haciendo un recuento como después de una hermosa cosecha, y sentir alegre el corazón porque es todo nuestro aunque lo dejemos aquí, aunque vengan los demás a quitarnos el sitio, ese pequeño sitio.

Si sabemos marcharnos diciendo: "Hasta mañana», nos quedaremos para siempre y nos lo llevaremos todo en nosotros.

Mirad. La primavera ha vuelto perezosa y transparente, y se incuba en el mundo, y es un cálido jugo en nuestras venas, un limpio rebrotar de fresas, de mañanas y de pájaros.

Doña Blanca de los Ríos acaba de encontrar un documento viejo, y le raspa la tinta, y los ojos le brillan porque ahora resulta que Gabriel Téllez era hijo natural del Duque de Osuna. Y sino (sic) vengan ustedes a su obra y verán las alusiones amargas, intencionadas:

«La desvergüenza en España

se ha hecho caballería.»

¿Si ya lo decía yo! - se ufana doña Blanca-(Luego vendrán otros señores a llevarle respetuosamente la contraria, pero por ahora ella, la pobre, ¡está tan contenta!).

Está abierto el balcón del Seminario, y dentro de un marco se ve un poco de llano derramado allá lejos y unas nubes delgadas que se estiran encima. $Y$ delante, más cerca, la ciudad con sus tejados dormidos, tibia como un humo. Todas las campanas de los conventos dan vueltas lentamente en la tarde.

Siempre ha vuelto así la primavera. Día tras día cada uno se ha ido encerrando en sus cosas y ha ido haciéndose distinto, pero siempre al andar se tropezaba con los ojos calientes de ese puñado de gentes amigas, y de pronto era bueno vivir, y era bueno mirar que la tarde caía en los conventos y que los árboles se habían llenado de flores blancas mientras partía el Cid para el destierro, mientras Manolo Ballestero divagaba apasionadamente, contradiciéndose, o ensayábamos teatro en la clase grande.

Ronsard nos lo ha dicho:

... «Vivez si m' en croyez, n'attendez á demain...»

Y Juan Ramón, ese estremecido poeta: 
«No busques, alma, en el montón de ayer

las perlas en la escoria...»

Ni mañana ni ayer. Ahora es todo nuestro. Podemos soñar que siempre será nuestro ¿No sentís clavado el instante como una aguja florecida? [¿] no os duele en el corazón su plenitud?

Esfuerzo elástico por saber, por probar; posibilidad, anhelo, ramas verdes cruzadas.

Sí. Estrenemos esta primavera. Porque nos hemos detenido y aún estábamos aquí, como siempre.

¿Escucháis? ¡Despertad! Aquí y ahora. Las nubes desplegadas cauce allá, sobre la torre.

En Salamanca, en Anaya a 15 de marzo de 1948.

\section{Historia de un mendigo (Martín Gaite, 1950)}

El mendigo llegó a la gran ciudad en una tarde clara y fría, con un zurrón y un perro compañero de los caminos. El perro no era suyo ni de nadie y por eso ni siquiera quiso ponerle nombre. Le llamaba sólo perro o perrucho, y el perro atendía a brincos. Tenía los ojos húmedos y cariñosos. Pero el mendigo pensaba: "Un día se me irá, y hará muy bien. Si encuentra un amo rico, con derecho a esclavizarle, ése le pondrá nombre». El perrillo saltaba con el rabo enhiesto cuando entraron en la gran ciudad. El poniente rojo se volcaba sobre unos andamios.

El mendigo era un viejo mendigo. No decrépito. No lisiado. Alto y anguloso, de barba pálida, de mirada aguda y serena. A nadie le importaba saber de dónde había venido, y nadie se lo preguntó. La verdad es que él tampoco era amigo de buscar oyentes; apenas le importaba a él mismo el cúmulo de días vividos. Y pensaba en sí muy raras veces.

El mendigo se decía: “¡Vaya! ¡Qué fáciles son las cosas! Ya estoy en la gran ciudad". Y se lo repetía muchas veces para enterarse y su idea iba con él mientras andaba como el rumor de un abejorro terco. Su idea se le repetía multiplicada en la voz de los claxons, de las ruedas, de los silbatos.

El mendigo se perdía entre los ruidos de la gran ciudad, vagando lentamente con su perro.

Un día se va lento o fugaz, pero notamos su peso y su medida. Si se juntan varios días ya no sabemos. Parece que los han soplado, que no son tiempo. Si se juntan diez, veinte lentos días ya no sabemos nada de ellos. 


\section{El mendigo pensaba:}

"Ya debe hacer un mes que estoy en la ciudad. El aire es templado y olerá a tomillo más allá de las casas». Las casas se alzaban como tapaderas impenetrables con su faja de sol en los pisos altos. Miles de casas. El mendigo levantaba sus ojos a los balcones. De alguno colgaba a veces, lacia, una palma cruzada desde el Domingo de Ramos; en otro se adivinaban unos tiestos. Luego los visillos tapaban lo de dentro. El mendigo notó que en aquella ciudad las mujeres no se asomaban nunca al balcón. En cambio había letreros sujetos a los hierros. Y por la noche se encendían y se apagaban con luz roja, verde, morada, insistente - Restaurante. Anís-Santrería (y la «a» rota se velaba como una luna en eclipse)-. Sobre las altas terrazas, el cielo se perdía detrás del halo rojizo y denso de los letreros.

Una tarde, siguiendo con la vista la herida púrpura de una nube, el mendigo y el perro fueron a parar a una plaza apartada que tenía una iglesia, dos tabernas y un farol. Era un sitio tranquilo y los niños se perseguían con las piernas sucias y desnudas por las bocacalles, desbocados, primaverales. El mendigo aprendió a ir allí desde cualquier calle desconocida. Iban siempre -él y el perro-al acabar la jornada, después de haberse fundido en el afán de la ciudad y de haberla visto girar con sus mil rostros y sus mil vitrinas y sus mil bombillas.

El mendigo descansaba la espalda contra la pared y rascaba el lomo del perro que gruñía con los ojos cerrados. Luego se iban a dormir entre los muros de una casa derruida desde la guerra que descubrieron un día en las afueras.

No siempre iban juntos. A veces al despertar, el perro se había marchado por su cuenta. Andaba todo el día separado del hombre, buscando su comida, y volvía a la noche a la plazuela. Allí esperaba a su amigo sentado en las escaleras de la iglesia. Otras veces le saludaba ladrando al llegar cuando el mendigo ya estaba alli, apoyado en la pared, pensando de cara a los astros: "Hoy no volverá más el perrucho. Y hará bien». Entonces se miraban hondamente, sin alborotar, pero el hombre sentía escozor en los ojos y se decía «Ha vuelto, vuelve porque quiere».

Al anochecer la ciudad se abría como un ascua de rumores y luz y las gentes se apresuraban hacia los tranvías, hacia el cruce de dos calles, hacia la entrada de un teatro. Un hombre serio, que iba pensando en Nietzsche, se cruzaba con una florista joven; un estudiante de medicina miraba las piernas de la florista desde el autobús; la muchacha del sombrerito rojo pensaba que era perfecto el perfil del estudiante, y su novio le tiraba de la manga: 
— «Nena, bajamos en la próxima». Se encendía la luz roja y el guardia daba la señal para cruzar. Todos se agolpaban, se separaban. La luz roja otra vez.

El mendigo observaba el ir y venir de las gentes con los ojos tranquilos. Los rostros eran alargados, carnosos, picudos, nunca los mismos. Él no los conocía. Tendía hacia ellos la mano mecánicamente, sin palabras. Aquellas monedas le hacían falta para comer un poco. ¿Qué más daba además ensayar un gemido o una ceguera? Las gentes pasaban con sus rostros distintos sin mirarle, sin conocerse. Pasaban los adolescentes, los hombres, preocupados y egoistas (sic), las muchachas pegadas a un novio. El mendigo los seguía con una mirada de ardiente curiosidad. ¿Cómo acercarse a ellos? ¿Cómo acercarse? A veces deseaba hablarles, pero hubiesen recelado. Si alguien le miraba alguna vez - el tabernero, la mujer de las cerillas, otro pobre-era desde un pozo de recelo. Pero eso se callaba.

El mendigo solía embriagarse alguna vez. Nunca del todo porque no tenía dinero. Después se dormía bien en cualquier sitio. Antes del sueño venían mezclados todos los rostros humanos, sonriéndole, y se besaban entre sí en una confusa armonía. Y formaban como un techo de lianas sobre su cabeza. El mendigo entreabría los ojos y en cada una de las estrellas de la noche veía su rostro. Luego los cerraba y en cada rostro de los de su sueño se encendía una estrella.

Cuando vino el verano, surcado de muchachas con los brazos desnudos, de mangueros y de algún pregón perezoso, el mendigo empezó a notarse desasosegado e insatisfecho como nunca en su vida: "'Qué cansado estoy!" -pensó. Y se extrañaba de aquello. Él, que nunca había pensado en hacer nada, se decía ahora: «Si fuera joven trabajaría y ganaría dinero para repartirlo, para regalarlo. Seguramente me casaría para tener hijos y, sino (sic), me acercaría a los niños de los demás y los besaría. Me gustaría pararme a la sombra de los árboles a echar un cigarro con los otros mendigos y escucharles su vida. Conocería la alegría de trabajar, y ella me uniría a las gentes».

Pero el mendigo se sentía impotente y viejo. Pensó: Tal vez estoy enfermo y me voy a morir. ¡Dios mío! Sería horrible morir aquí, tan solo.

Y una mañana se echó su zurrón al hombre y se fue de la ciudad furtivamente, con las primeras luces, hacia donde maduran los trigales.

Camino adelante. Camino de la muerte.

El perro le siguió. 


\section{Referencias bibliográficas}

Alemany Bay, Carmen (1990). La novelística de Carmen Martín Gaite. Salamanca: Ediciones de la Diputación de Salamanca.

Brown, Joan Lipman (1987). Secrets from the Back Room: the Fiction of Carmen Martín Gaite. Mississipi: University of Mississipi.

Chown, Linda E. (1990). Narrative Authority and Homeostasis in the Novels of Doris Lessing and Carmen Martín Gaite. New York: Garland.

CiplijausKaité, Biruté (1988). La novela femenina contemporánea (1970-1985). Hacia una tipología de la narración en primera persona. Barcelona: Anthropos.

GraCiA, Jordi (1994). Crónica de una deserción. Ideología y política en la prensa universitaria del franquismo (1940-1960). Barcelona: PPU.

Lluch Villalba, M. ${ }^{a}$ de los Ángeles (2000). Los cuentos de Carmen Martín Gaite. Navarra: Ediciones de la Universidad de Navarra.

MARTín GaITE, Carmen (1947a). «La barca nevada». Trabajos y Dias 5, s. p.

- (1947b). «Poetas rumanos: Tudor Arghezi: Los muertos y Duhovniceasca». Trabajos y Días 6, s. p.

- (1948). «Desde el umbral». Trabajos y Días 9, 7.

- (1949a). «En mi vejez». Trabajos y Días 11, 5.

- (1949b). «Destello». Trabajos y Días 11, 5.

- (1950). «Historia de un mendigo». Trabajos y Días 13, 18-19.

- (1993). Agua pasada. Barcelona: Anagrama.

MARTINEll Gifre, Emma, ed. (1993). Carmen Martín Gaite, Madrid: Instituto de Cooperación Iberoamericana.

Nichols, Geraldine (1992). Des/cifrar la diferencia. Narrativa femenina de la España contemporánea. Madrid: Siglo Veintiuno de España Editores.

PelÁeZ DEL Rosal, Manuel (1980). «Publicaciones periódicas de la Universidad de Salamanca (1946-1980)». En Catálogo de revistas, 9-14. Salamanca: Universidad de Salamanca.

Puente Samaniego, Pilar de la (1994). La narrativa breve de Carmen Martín Gaite. Salamanca: Plaza Universitaria Ediciones.

RodRíGUEZ DE LA FLOR, Fernando (1980). «Trabajos y Días, una revista de Salamanca de los años cuarenta». El Adelanto, 18 de mayo.

ROMERo LÓPEZ, M. ${ }^{a}$ Dolores (1995). «Un tributo al análisis de las revistas españolas de posguerra: Trabajos y Días (Salamanca, 1946-1951)». Revista de Estudios (Salamanca) 35-36, 243-272.

SANTANDER, Teresa, ed. (1986). Publicaciones periódicas salmantinas existentes en la biblioteca universitaria (1783-1981). Salamanca: Biblioteca Universitaria.

Servodidio, Mirella y Welles, Marcia L., eds. (1983). From Fiction to Metafiction: Essays in Honor of Carmen Martín Gaite. Lincoln, Nebraska: Society of Spanish and Spanish-American Studies. 